\title{
(D) Prospective cohort study examining the use of OPEN ACCESS regional anesthesia for early pain management after
combat-related extremity injury
}

\author{
Rollin M Gallagher, ${ }^{1}$ Rosemary C Polomano, ${ }^{2,3}$ Nicholas A Giordano (D) ,,5 \\ John T Farrar, ${ }^{6}$ Wensheng Guo, ${ }^{6}$ Lynn Taylor, ${ }^{6}$ David Oslin, ${ }^{7,8}$ Brandon J Goff, ${ }^{9}$ \\ Chester C Buckenmaier ${ }^{4,5}$
}

Additional material is published online only. To view, please visit the journal online (http://dx.doi.org/10.1136rapm2019-100773).

For numbered affiliations see end of article.

\section{Correspondence to} Dr Chester C Buckenmaier, Defense \& Veterans Center for Integrative Pain Management, Rockville, Maryland 20852, USA; cbuckenmaier@dvcipm.org

Received 13 June 2019 Revised 19 August 2019 Accepted 9 September 2019 Published Online First 27 September 2019

\section{Check for updates}

(C) American Society of Regional Anesthesia \& Pain Medicine 2019. Re-use permitted under CC BY-NC. No commercial re-use. Published by BMJ.

To cite: Gallagher RM, Polomano RC, Giordano NA, et al. Reg Anesth Pain Med 2019:44:1045-1052.

\begin{abstract}
Background No studies have examined the longterm benefits of regional anesthesia (RA) for pain management after combat-related injury. The objective of this prospective cohort study was to examine the relationship between RA administration and patientreported pain-related outcomes among Operation Enduring Freedom (OEF) and Operation Iraqi Freedom (OIF) service members sustaining a combat-related extremity injury.
\end{abstract}

Methods Between 2007 and 2013, n=358 American military personnel injured in OEF/OIF were enrolled at two military treatment facilities. Individuals were followed for up to 2 years after injury. Cohorts were defined based on whether participants were administered RA within 7 days after sustaining a combat-related injury, or not. Linear mixed effects models examined the association between RA and average pain intensity. Secondary outcomes included pain relief, pain interference, neuropathic pain symptoms, treatment outcomes related to pain management, and mental health symptoms.

Results Receiving early RA was associated with improved average pain over the first 6 months after injury ( $\beta=-0.57 ; p=0.012$ ) adjusting for injury severity and length of stay at the primary treatment facility. This difference was observed up to 24 months after injury $(\beta=-0.36 ; p=0.046)$. Individuals receiving early RA reported greater pain relief, improved neuropathic pain intensity, and higher satisfaction with pain outcomes; however, by 24 months, mean scores did not significantly differ between cohorts.

Conclusion Findings indicate that when administered soon after traumatic injury, RA is a valuable pain management intervention. Future longitudinal studies investigating the timely delivery of RA for optimal pain management in civilian trauma settings are needed. Trial registration number NCT00431847

\section{INTRODUCTION}

Improving acute pain management after traumatic injury remains a priority for policymakers and clinicians as rates of injury and subsequent painrelated disability rise nationally. ${ }^{12}$ Yet, innovations in trauma pain management remain understudied. Advances in combat casualty care have contributed toward historically high survival rates, creating an unprecedented number of survivors living with once fatal injuries from Operation Enduring Freedom $(\mathrm{OEF})$ and Operation Iraqi Freedom (OIF). ${ }^{3}$ Rates of chronic pain among survivors of combat-related injuries surpass $80 \% .^{45}$ Many who suffer from chronic pain also experience post-traumatic stress disorder (PTSD), traumatic brain injuries (TBI), depression, and reduced physical function. ${ }^{6}$ Survivors require substantial and costly long-term treatment, rehabilitation, and pain management.

Adequately managing acute pain in the immediate postinjury period may reduce chronic pain and thereby enhance rehabilitation and recovery efforts. Battlefield pain management has been associated with decreased acute pain intensity and reduced psychological sequelae. ${ }^{7-9}$ Regional anesthesia (RA) can block afferent painful stimuli, decrease acute pain intensity, and possibly prevent central sensitization and the subsequent development of chronic pain. ${ }^{10}$ Previous research examining RA for the prevention of chronic pain has been limited to studies often with less than 12 months of follow-up and conducted in postoperative civilian populations. ${ }^{11}$

The mass mobilization of personnel at the onset of OEF/OIF required the rapid development of an infrastructure capable of caring for the combatinjured. As such, not all anesthesia providers were trained in RA administration before being deployed to military treatment facilities. ${ }^{12}$ We leveraged the variability in the availability of RA administration in the height of these armed conflicts as a natural research opportunity to evaluate the potential benefits of receiving early RA for pain management. This study evaluated patient-reported pain outcomes in OEF/OIF service members and veterans with combat-related extremity injuries. We hypothesized that individuals receiving early RA, defined as a continuous peripheral nerve block (CPNB) within 7 days of injury, would experience reduced average pain intensity in the 24 months after injury compared with those who did not. We designed our study to characterize long-term secondary outcomes of neuropathic pain, health-related quality of life (HRQOL), and psychological symptoms, after combat-related injury.

\section{METHODS}

Study design

This was a prospective, observational, repeated measures investigation of combat-injured service 


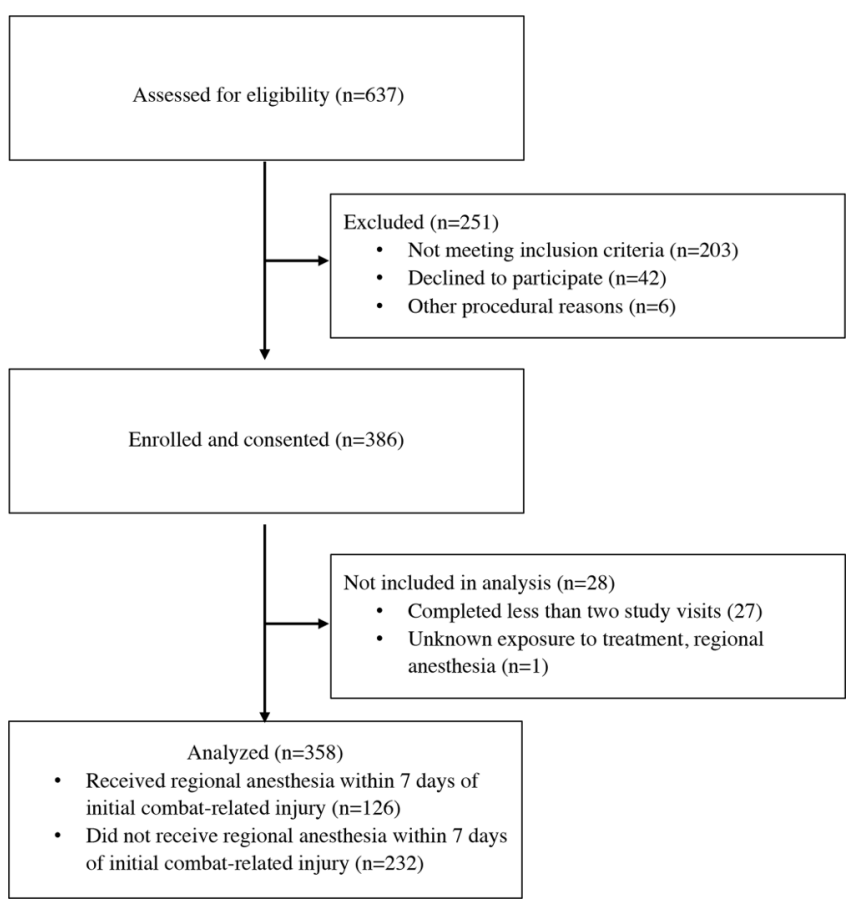

Figure 1 Screening and study enrollment.

members with or without exposure to early RA. Research nurses recruited and consented patients during their acute hospitalization or inpatient rehabilitation from October 2007 to November 2013 at Walter Reed National Military Medical Center, formerly Walter Reed Army Medical Center, Bethesda, Maryland, and San Antonio Military Medical Center, formerly Brooke Army Medical Center, San Antonio, Texas. Researchers collected patient-reported outcomes using scripted telephone interviews. Extensive efforts were needed to collect data due to the many difficulties in follow-up for this population. Transitions in care for OEF/OIF service members after injury entailed: (1) combat support hospital trauma care in Iraq or Afghanistan; (2) evacuation to Landstuhl Regional Medical Center, Germany; (3) transfer to stateside military hospitals (eg, mentioned recruitment sites); (4) discharge from initial acute care hospitalization; (5) discharge to Medical Center Campus Housing; (6) outpatient rehabilitation; and (7) returning home across the USA. Exhaustive attempts were made to collect outcomes as often as possible, with attempts made monthly within the first 6 months after injury and in 3-month intervals up to 24 months after injury (online supplementary table S1). The complex trajectory of transitions in care, in combination with the prospective observational nature of the study design, resulted in incomplete data collection at the standardized collection points.

\section{Regional anesthesia}

Depending on the capabilities of the frontline anesthesia providers, service members received a CPNB or not, in addition to routine systemic multimodal analgesia, either during evacuation or within 7 days of initial hospitalization at military treatment facilities. RA is best when administered immediately after injury but the realities of the evacuation environment made it difficult to know the exact timing of administration. Within 7 days was selected considering most casualties were medically stabilized within this time frame as they processed through combat support hospitals in Iraq or Afghanistan, then moved to Landstuhl Regional Medical Center for definitive care, before being transferred to the USA. Causalities who received CPNB within 7 days overwhelmingly received their intervention in theater or at Landstuhl. The designation of "early RA," in the context of this manuscript, represents the acute nature of care received within 1 week of the trauma.

The deployment of military anesthesia providers during OEF/ OIF was made without regard to their RA training, thereby creating a non-differential likelihood of any trauma victim's exposure to RA treatment. Combat-injured patients received RA whenever a trained provider was present at the facility to which they were evacuated. This created an opportunity to compare outcomes between reasonably equivalent groups of combatinjured personnel. In the combat theater, anesthesia providers used a wide array of catheter placements, and medications, based on their clinical expertise and their patients' injuries. Variability across providers' clinical practices, in conjunction with the challenges of documenting medication used in the active war zone, limited the availability of data on the specific medications and dosing regimens. ${ }^{13}$

Both the early RA and usual care groups also received routine, opioid-based, systemic analgesia. Combat-injured personnel were routinely followed by acute pain service providers with access to all classes of parenteral analgesics and other pain interventions. Some participants also received RA later in their care, independent of their early RA status, which was typically provided when additional pain management was required (eg, during wound debridement).

\section{Study population}

This sample was drawn from OEF/OIF service members transferred to the two stateside treatment facilities designated to provide definitive postinjury care. Estimates show that half of all wounds sustained during OEF/OIF were extremity injuries. ${ }^{14}$ Therefore, all service members with a combat-related extremity injury severe enough to require hospitalization and inpatient rehabilitation were eligible to be screened for this study. Individuals with severe cognitive deficits or hearing loss due to head trauma, and bilateral upper extremity amputation with no alternate means to complete surveys, were excluded. Nurses determined the cognitive capacity of participants during recruitment, and those with obvious cognitive deficits due to TBI were excluded. Other procedural issues limited participation, including participants being transferred to another facility after eligibility screening but prior to obtaining consent. Among individuals consented and enrolled, those with a known RA exposure status and having at least two study observations were included in the analysis (figure 1).

RA exposure, demographics, injury characteristics, and clinical data were collected from the Joint Theater Trauma Registry (JTTR). Mechanism, injury location, and Injury Severity Scores (ISS) in JTTR were verified with participants. Measured from 0 to 75 , the ISS correlates with mortality and morbidity. ${ }^{15}$

\section{Study outcomes}

The primary outcome was the average pain intensity measured using the Brief Pain Inventory (BPI). The BPI measures average, worst, and least pain over the past week on a scale from 0 , "no pain," to 10, "pain as bad as you can imagine." ${ }^{16}$ Using this validated measure, participants rate the degree to which pain interfered with functioning, general activity, mood, walking, work, relationships, sleep, and enjoyment of life on a scale from 0 , "does not interfere," to 10, "completely interferes." An average of the interference questions was computed. Pain relief due to 
pain treatment is measured from $0 \%$, none, to $100 \%$, complete relief in the past week.

Measuring the multidimensional nature of complex combat injury pain is improved by using several instruments, each assessing unique theoretical domains. The 10-item Neuropathic Pain Scale (NPS) assesses distinct qualities of neuropathic pain and has been validated with multiple chronic pain populations. ${ }^{17}$ Responses range from 0 , "no sensation," to 10, "the most sensation imaginable." Scores were averaged for an overall total score and categorized into two subscales, pain intensity and pain quality. The validated 120-item Treatment Outcomes of Pain Survey (TOPS) captures participants' pain characteristics and treatment responses across 14 subscales. ${ }^{18}$ Scores range from 0 , "pain does not impact health," to 100, "pain completely impacts health." All eight subscales of the Short Form 36-Item (SF-36), an HRQOL measure, are in the TOPS. SF-36 subscale scores are transformed to T-scores, and standardized to a general population, with a mean of $50( \pm 10) .{ }^{19}$ The SF-36 physical (PCS) and mental health component scores (MCS) are each aggregated from the subscales. The Patient Health Questionnaire 9-Item (PHQ-9) assessed the Diagnostic and Statistical Manual of Mental Disorders IV (DSM-IV) criteria for depression. ${ }^{20}$ The PTSD Check List (PCL) assessed the extent to which participants' experienced DSM-IV PTSD symptoms over the last month from 17 to $85 .^{21}$

\section{Statistical analysis}

Descriptive statistics were used to examine demographic and injury characteristics. Univariate tests were used to assess whether there were any systematic differences between the treatment groups. Linear mixed effects models were used to examine if longitudinal changes in average pain and secondary outcomes were associated with early RA administration. While participants were enrolled at various stages of recovery and data collection months varied within subjects, for the analysis, all individual data points were lined up in a unified approach by using the time from initial injury to data collection point. All models included a random intercept and slope to account for correlations among the observations within a subject. When examining treatment effects, those who did not receive early RA served as the reference group. To account for the severity of the initial injury, we included two covariates as possible confounders: ISS (ie, injury severity) and length of acute care, in days, at the recruitment facility (eg, length of stay). Both ISS and length of stay after injury were included as potential confounders to account for clinical variation and possible effect on pain outcomes. ISS was included as a direct measure of injury, and length of stay as a secondary measure of injury severity. Isolating the potential benefits gained from RA can be difficult to discern among the myriad of biological and psychosocial changes that can influence pain-related outcomes combat-injured service members experience. Given the hypothesized benefits of RA, average pain and other patient-reported pain-related outcomes were examined in the first 6 months postinjury and over the 24-month period. Post hoc analyses indicated that the present sample size achieved sufficient power to detect a medium effect size in the observed differences between the slopes of the RA groups on the repeated outcomes of interest (eg, average pain) both at 6 months, $0.82 \%$, and at 24 months, 0.99\%, with an alpha level of 0.05 (PASS V.16, NCSS, LLC, Kaysville, Utah, USA). The effect size was computed based on (1) the two slope means (eg, rate of change between RA groups); (2) the average person level SD across repeated measures; (3) a base correlation of 0.20 between time points; and (4) a compound symmetry pattern of correlation across time. Due to the hypothesis-generating nature of this study, secondary outcomes and subgroup analyses are exploratory and therefore, not adjusted for multiple comparisons. Analyses were conducted in SAS V.9.4 with a two-sided significance level of 0.05 .

As stated previously, subjects were recruited during either inpatient hospitalization or inpatient physical rehabilitation at the only two military treatment facilities in the continental USA capable of managing the immediate care needs of military personnel with combat-related extremity injuries. As such, the study was designed to capture up to 12 observations per subject if they were recruited within the first month since their initial injury. However, the reality of enrolling subjects and capturing their initial outcomes during this difficult and intensive care period proved difficult. The team attempted to systematically recruit all eligible subjects after their acute hospitalization and control for the time between individual subject's baseline measures and their initial injury that might have confounded outcomes. Individuals could enter the study at any time point of their hospitalization or rehabilitation and provide data within 24 months of their initial injury. As such, participants' baseline measures varied. To mitigate potential biases, the models used in this analysis estimated outcomes from the time since initial injury so that all data points were adjusted to a common standardized time.

Several interaction terms were evaluated to assess for potential biases. We divided the cohort into subgroups based on the time between participants' entry into the study and their initial injury. Interactions between the subgroups and RA were used to determine whether any biases were due to different stages of enrollment. The interactions were not statistically significant, indicating that there were no detectable systematic biases due to enrollment stages. We tested the treatment to year-of-injury interaction to see whether the trends in RA receipt differed. None of the treatment and time interactions were significant and therefore, were excluded from the final model. Based on these null results, intermittent missing data were treated as missing at random. Sensitivity analyses were conducted to evaluate if there were differences in treatment effects between the dropouts and those who completed the study, by testing the interaction between dropout indicator and treatment group, which was not significant. We also stratified the cohort into subgroups based on the number of observation points in the study and tested whether the different durations introduced biases in the treatment effect by testing the interaction of the duration and treatment interaction. This interaction was not significant either.

\section{RESULTS}

\section{Participant characteristics}

The final sample included 358 participants, of which 126 received early RA and 232 who did not. The mean age was $28( \pm 7.5)$ years and participants were predominantly non-Hispanic Caucasian males (table 1$)$. On average, subjects had $6( \pm 3)$ observations and there was no statistically significant difference in the number of observations by RA cohort. Compared with the usual care group, statistical differences were noted for the following: in the proportion of college-educated service members who received early RA, $25.4 \%$ vs $14.2 \%(p=0.032)$; the proportion of Marines who received early RA, $11.1 \%$ vs $23.7 \%(p=0.015)$; individuals with explosion inflicted injuries who received early RA, $82.5 \%$ vs $72.4 \%(p=0.032)$; the proportion of individuals with a head injury who received early RA, $61.9 \%$ vs $50.9 \%(p=0.046)$; the proportion of individuals with arm injuries who received early 


\begin{tabular}{|c|c|c|c|}
\hline & $\begin{array}{l}\text { No early regional* } \\
\text { anesthesia }(n=232)\end{array}$ & $\begin{array}{l}\text { Early regional }{ }^{*} \\
\text { anesthesia }(n=126)\end{array}$ & $P$ value \\
\hline & $(n=232)$ & & \\
\hline Age, mean (SD), y ${ }^{\dagger}$ & $28.0(7.5)$ & $28.2(6.3)$ & 0.751 \\
\hline Sex & & & 0.555 \\
\hline Female & $3(1.3)$ & $0(0.0)$ & \\
\hline Male & $229(98.7)$ & $126(100.0)$ & \\
\hline Race & & & 0.616 \\
\hline White & $117(76.3)$ & $101(80.2)$ & \\
\hline Black & $14(6.0)$ & $5(4.0)$ & \\
\hline Other & $41(17.7)$ & $20(15.9)$ & \\
\hline Ethnicity & & & 0.540 \\
\hline Non-Hispanic & 201 (86.6) & $112(88.9)$ & \\
\hline Hispanic & $31(13.4)$ & $14(11.1)$ & \\
\hline Education & & & 0.032 \\
\hline High school/GED & $100(43.1)$ & $47(37.3)$ & \\
\hline Some college & $99(42.7)$ & $47(37.3)$ & \\
\hline College graduate & $33(14.2)$ & $32(25.4)$ & \\
\hline Marital status & & & 0.098 \\
\hline Single/never married & $115(49.6)$ & $51(40.5)$ & \\
\hline Married/partnered & $102(44.0)$ & $70(55.6)$ & \\
\hline Separated/divorced & $15(6.5)$ & $5(4.0)$ & \\
\hline Military service & & & 0.015 \\
\hline Army & $165(71.1)$ & $105(83.3)$ & \\
\hline Marine & $55(23.7)$ & $14(11.1)$ & \\
\hline Other & $12(5.2)$ & $7(5.6)$ & \\
\hline $\begin{array}{l}\text { Number of deployments, } \\
\text { mean }(S D) \dagger\end{array}$ & $1.9(1.2)$ & $2.1(1.3)$ & 0.083 \\
\hline $\begin{array}{l}\text { Length of last deployment, } \\
\text { mean (SD), m† }\end{array}$ & $4.5(2.7)$ & $4.4(2.9)$ & 0.757 \\
\hline $\begin{array}{l}\text { Injury Severity Score, mean } \\
\text { (SD)† }\end{array}$ & $19.0(11.8)$ & $17.3(8.5)$ & 0.170 \\
\hline \multicolumn{4}{|l|}{ Mechanism of injury } \\
\hline Explosion & $168(72.4)$ & $104(82.5)$ & 0.032 \\
\hline Gunshot & $40(17.2)$ & $16(12.7)$ & 0.258 \\
\hline Motor vehicle & $13(5.6)$ & $4(3.2)$ & 0.302 \\
\hline Other & $17(7.3)$ & $4(3.2)$ & 0.110 \\
\hline \multicolumn{4}{|l|}{ Injury type } \\
\hline Amputation & $71(31.0)$ & $60(47.6)$ & 0.002 \\
\hline Arm injuries & $117(51.1)$ & $78(61.9)$ & 0.046 \\
\hline Leg injuries & 191 (83.4) & $107(84.9)$ & 0.723 \\
\hline Mangled limb & $225(98.3)$ & $120(95.2)$ & 0.099 \\
\hline $\begin{array}{l}\text { More than one extremity } \\
\text { injury }\end{array}$ & $63(27.5)$ & $36(28.6)$ & 0.812 \\
\hline Head injury & 117 (50.9) & $78(61.9)$ & 0.046 \\
\hline $\begin{array}{l}\text { PTSD Check List, mean } \\
\text { (SD) } \dagger\end{array}$ & 27.7 (11.9) & $27.5(12.5)$ & 0.889 \\
\hline $\begin{array}{l}\text { Length of stay at } \\
\text { recruitment site, mean } \\
\text { (SD), d }\end{array}$ & $34.3(34.1)$ & $41.1(30.5)$ & 0.063 \\
\hline Current smoker & $41(17.7)$ & $13(10.3)$ & 0.063 \\
\hline Previous head trauma & $132(57.1)$ & $63(50.0)$ & 0.195 \\
\hline
\end{tabular}

${ }^{*}$ Data are presented as number (percentage) of participants unless otherwise indicated. tRefers to t-test, otherwise results refer to $\chi^{2}$ analyses.

d, days; GED, general education development; $m$, months;PTSD, post-traumatic stress disorder; $y$, years.

RA, $61.9 \%$ vs $51.1 \%(\mathrm{p}=0.046)$; and the proportion of individuals with sustained injuries resulting in an amputation, $47.6 \%$ vs $31.0 \%(p=0.002)$. Despite differences, none were statistically significantly associated with the outcomes in the multivariable analysis. Subsequent bivariate testing indicated that the inclusion of ISS in the modeling accounted for the heterogeneity in injury

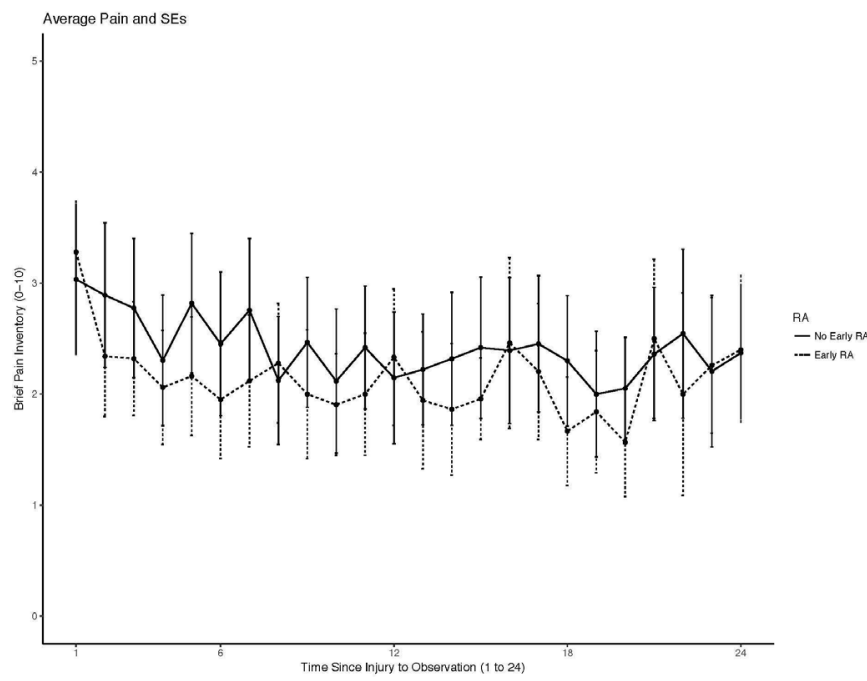

Figure 2 Despite the severity of injuries, Brief Pain Inventory average pain scores improved over time for both groups. Individuals who received early regional anesthesia (RA) had similar average pain scores even though their average pain scores were elevated in the first few months after injury.

types. Research indicates an association between not completing a high-school education/general education development (GED) and lower physical health among healthy populations of service members. ${ }^{22}$ All participants in this sample had obtained a highschool education/GED and the inclusion of this variable in the multivariable modeling showed no changes in outcomes. There was no statistically significant difference in the mean ISS with individuals in both RA groups presenting with moderate-to-verysevere injuries. The ISS and RA interaction was also not statistically significant indicating that there was no difference in the pain outcomes among severely injured participants who did or did not receive early RA compared with those with less severe injuries. Injury types were not mutually exclusive due to the polytrauma nature of the injuries. Cohorts were well-balanced despite the nature and severity of their injuries.

\section{RA and average pain intensity}

On average, pain scores decreased over time across the entire cohort (figure 2). After adjusting for length of stay and ISS, there was a significant association between receiving early RA and reduced average pain intensity (figure 3 ). Average pain intensity BPI scores were estimated to be over half a point lower in the early RA group in the first 6 months after injury $(\beta=-0.57 ; 95 \% \mathrm{CI}$ -1.02 to $-0.13 ; \mathrm{p}=0.012$ ) (table 2 ). Individuals receiving early RA were estimated to experience average pain scores of 2.5 compared with 3.1 in those who did not, when adjusted for time, ISS, and length of stay. A slightly smaller difference in the reduction of average pain intensity after receiving early RA was observed up to 24 months $(\beta=-0.36 ; 95 \% \mathrm{CI}-0.72$ to -0.01 ; $\mathrm{p}=0.046)$. Average pain intensity significantly decreased per month over the 24 -month period ( $\beta=-0.03 ; 95 \% \mathrm{CI}-0.04$ to $-0.02 ; \mathrm{p}<0.001)$ in both groups, but again with a larger difference in pain scores observed in the early RA group.

\section{Secondary outcomes}

Receiving early RA was associated with $6.36 \%$ increase in patient-reported pain relief in the first 6 months after injury (95\% CI $0.40 \%$ to $12.31 \% ; \mathrm{p}=0.037$ ) (table 2 ). This translates to an estimated $72.48 \%$ pain relief response among individuals 


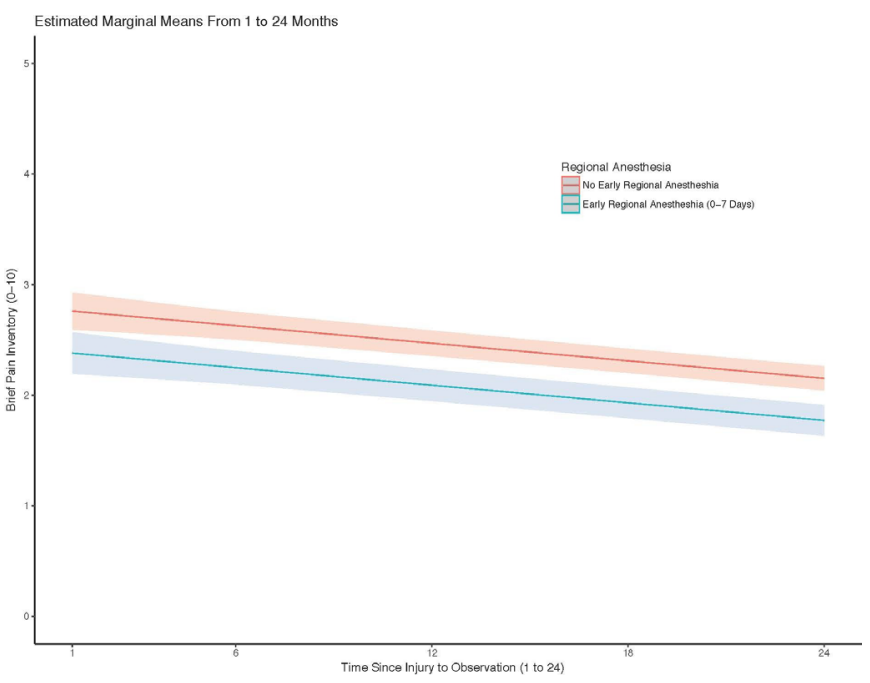

Figure 3 Estimated marginal means and $95 \%$ Cls of average pain scores from linear mixed effects model. Average pain intensity BPI scores were estimated to be over half a point lower in the early regional anesthesia group in the initial 6 months after injury $(\beta=-0.57 ; 95 \% \mathrm{Cl}$ -1.02 to $-0.13 ; p=0.012$ ) (see online supplementary table 2 ). When the model is applied to the 24-month horizon, the significant difference in average pain intensity remains $(\beta=-0.36 ; 95 \% \mathrm{Cl}-0.72$ to -0.01 ; $\mathrm{p}=0.046)$. BPI, Brief Pain Inventory.

who received early RA compared with $66.12 \%$ for those who did not. Pain relief did not significantly change by month after 6 months and no statistical difference between RA groups was observed at 24 months. Both worst pain intensity and pain interference improve equally across RA groups. For both RA groups, worst pain and pain interference BPI scores decreased monthly over the 24-month period when adjusting for length of stay and ISS with greater monthly differences seen in the initial 6-month period.
Overall, and at each time point, neuropathic pain intensity and total pain decrease equally across RA groups when adjusting for length of stay and ISS. Neuropathic pain intensity is estimated to decrease an average of 1 point by 24 months $(\beta=-0.04$; $95 \%$ CI -0.06 to $-0.03 ; \mathrm{p}<0.001$ ) (table 3 ). Similarly, total neuropathic pain scores $(\beta=-0.03 ; 95 \%$ CI -0.04 to -0.02 ; $\mathrm{p}<0.001)$ are estimated to improve with each month. In regard to the TOPS domains, fear-avoidance symptoms decreased $(\beta=-0.58 ; 95 \% \mathrm{CI}-0.78$ to $-0.38 ; \mathrm{p}<0.001)$, as did pain symptoms $(\beta=-0.35 ; 95 \% \mathrm{CI}-0.53$ to $-0.17 ; \mathrm{p}<0.001)$ and solicitous responses $(\beta=-1.12 ; 95 \% \mathrm{CI}-1.45$ to -0.80 ; $\mathrm{p}<0.001)$ at each time point across both RA groups. Individuals in both groups reported high satisfaction with pain treatment after their combat injuries, on average $(\beta=61.59 ; 95 \% \mathrm{CI}$ 56.77 to $66.40 ; \mathrm{p}<0.001)$. Early RA participants experienced improved secondary outcomes, on average, but differences were not statistically significant at 24 months after injury (table 3 ).

Mental health outcomes did not significantly change over the study period in either RA group. Average MCS scores were 5 points above mean mental health scores of the general American population to which the SF-36 is normed to $(\beta=54.95$; $95 \%$ CI 52.30 to $57.59 ; \mathrm{p}<0.001)$. PCS scores in this sample were over a SD below the general population's average physical health $(\beta=38.36 ; 95 \%$ CI 35.78 to $40.94 ; p<0.001)$. PCS scores improved less than 1 point, on average each month after injury, for both RA groups (95\% CI 0.43 to 0.63 ; p < 0.001). PHQ-9 and PCL scores did not significantly change per month in either RA group when adjusting for length of stay and ISS.

\section{DISCUSSION}

The improvements in average pain and pain relief in the first 6 months after injury observed in our study indicate a strong association between receiving early RA after combat injury in the austere battlefield environment and improved long-term pain outcomes. Despite the variability introduced to the study by the difficulties inherent in data collection during a combat

Table 2 Patient-reported pain outcomes estimated from linear mixed effects model from 1-6 to 1-24 months after combat injury

\begin{tabular}{|c|c|c|c|c|c|c|}
\hline & \multicolumn{3}{|c|}{ 1-6 months } & \multicolumn{3}{|c|}{ 1-24 months } \\
\hline & $\beta$ & $95 \% \mathrm{Cl}$ & $P$ value & $\beta$ & $95 \% \mathrm{Cl}$ & $P$ value \\
\hline \multicolumn{7}{|l|}{ Brief Pain Inventory* } \\
\hline \multicolumn{7}{|l|}{ Average pain } \\
\hline Intercept & 3.11 & 2.63 to 3.60 & $<0.001$ & 2.76 & 2.38 to 3.13 & $<0.001$ \\
\hline Month since initial injury & -0.18 & -0.23 to -0.12 & $<0.001$ & -0.03 & -0.04 to -0.02 & $<0.001$ \\
\hline Regional anesthesia & -0.57 & -1.02 to -0.13 & 0.012 & -0.36 & -0.72 to -0.01 & 0.046 \\
\hline \multicolumn{7}{|l|}{ Pain relief } \\
\hline Intercept & 66.12 & 59.00 to 73.24 & $<0.001$ & 66.24 & 60.60 to 71.89 & $<0.001$ \\
\hline Month since initial injury & 0.48 & -0.61 to 1.56 & 0.389 & -0.50 & -0.78 to -0.21 & 0.001 \\
\hline Regional anesthesia & 6.36 & 0.40 to 12.31 & 0.037 & 3.82 & -1.23 to 8.88 & 0.137 \\
\hline \multicolumn{7}{|l|}{ Worst pain } \\
\hline Intercept & 5.70 & 5.02 to 6.37 & $<0.001$ & 5.14 & 4.61 to 5.67 & $<0.001$ \\
\hline Month since initial injury & -0.28 & -0.36 to -0.21 & $<0.001$ & -0.05 & -0.06 to -0.03 & $<0.001$ \\
\hline Regional anesthesia & -0.32 & -0.94 to 0.31 & 0.324 & -0.27 & -0.78 to 0.24 & 0.296 \\
\hline \multicolumn{7}{|l|}{ Pain interference } \\
\hline Intercept & 2.39 & 1.82 to 2.97 & $<0.001$ & 2.30 & 1.87 to 2.73 & $<0.001$ \\
\hline Month since initial injury & -0.16 & -0.22 to -0.09 & $<0.001$ & -0.04 & -0.05 to -0.02 & $<0.001$ \\
\hline Regional anesthesia & -0.24 & -0.77 to 0.29 & 0.371 & -0.15 & -0.56 to 0.26 & 0.479 \\
\hline
\end{tabular}

All models included a covariate for ISS and length of hospitalization. See online supplementary table 2 for more detail.

*Brief Pain Inventory outcomes worst, average, and pain interference range from 0, no pain, to 10, pain as bad as you can imagine. The Brief Pain Inventory pain relief is on a scale from $0 \%$, no pain relief, to $100 \%$, complete pain relief.

ISS, Injury Severity Scores. 
Table 3 Secondary outcomes estimated from linear mixed effects model from 1 to 24 months after combat injury

\begin{tabular}{|c|c|c|c|}
\hline & $\beta$ & $95 \% \mathrm{Cl}$ & $P$ value \\
\hline \multicolumn{4}{|l|}{ Neuropathic Pain Scale* } \\
\hline \multicolumn{4}{|l|}{ Pain intensity } \\
\hline Intercept & 3.37 & 2.92 to 3.81 & $<0.001$ \\
\hline Month since initial injury & -0.04 & -0.06 to -0.03 & $<0.001$ \\
\hline Regional anesthesia & -0.23 & -0.66 to 0.20 & 0.297 \\
\hline \multicolumn{4}{|l|}{ Overall pain quality } \\
\hline Intercept & 2.78 & 0.00 to 2.36 & 0.207 \\
\hline Month since initial injury & -0.20 & 0.00 to -0.25 & 0.157 \\
\hline Regional anesthesia & -0.12 & 0.56 to -0.51 & 0.277 \\
\hline \multicolumn{4}{|l|}{ Total pain score } \\
\hline Intercept & 2.55 & 2.22 to 2.88 & $<0.001$ \\
\hline Month since initial injury & -0.03 & -0.04 to -0.02 & $<0.001$ \\
\hline Regional anesthesia & -0.04 & -0.36 to 0.28 & 0.810 \\
\hline \multicolumn{4}{|c|}{ Treatment Outcomes of Pain Survey† } \\
\hline \multicolumn{4}{|l|}{ Fear avoidance } \\
\hline Intercept & 49.83 & 44.18 to 55.49 & $<0.001$ \\
\hline Month since initial injury & -0.58 & -0.78 to -0.38 & $<0.001$ \\
\hline Regional anesthesia & 1.73 & -3.62 to 7.09 & 0.525 \\
\hline \multicolumn{4}{|l|}{ Healthcare satisfaction } \\
\hline Intercept & 61.59 & 56.77 to 66.40 & $<0.001$ \\
\hline Month since initial injury & -0.34 & -0.55 to -0.14 & 0.001 \\
\hline Regional anesthesia & 3.83 & -0.70 to 8.35 & 0.097 \\
\hline \multicolumn{4}{|l|}{ Life control } \\
\hline Intercept & 75.43 & 70.05 to 80.81 & $<0.001$ \\
\hline Month since initial injury & -0.06 & -0.27 to 0.16 & 0.604 \\
\hline Regional anesthesia & 4.12 & -0.91 to 9.15 & 0.108 \\
\hline \multicolumn{4}{|c|}{ Objective family social disability } \\
\hline Intercept & 48.26 & 42.63 to 53.89 & $<0.001$ \\
\hline Month since initial injury & -0.20 & -0.42 to 0.02 & 0.075 \\
\hline Regional anesthesia & -1.20 & -6.54 to 4.14 & 0.659 \\
\hline \multicolumn{4}{|c|}{ Patient satisfaction with outcomes } \\
\hline Intercept & 64.45 & 59.70 to 69.19 & $<0.001$ \\
\hline Month since initial injury & 0.18 & -0.01 to 0.36 & 0.065 \\
\hline Regional anesthesia & 2.36 & -2.13 to 6.85 & 0.301 \\
\hline \multicolumn{4}{|l|}{ Pain symptom } \\
\hline Intercept & 40.18 & 35.02 to 45.34 & $<0.001$ \\
\hline Month since initial injury & -0.35 & -0.53 to -0.17 & $<0.001$ \\
\hline Regional anesthesia & -1.45 & -6.34 to 3.44 & 0.560 \\
\hline \multicolumn{4}{|l|}{ Solicitous response } \\
\hline Intercept & 55.32 & 47.45 to 63.19 & $<0.001$ \\
\hline Month since initial injury & -1.12 & -1.45 to -0.80 & $<0.001$ \\
\hline Regional anesthesia & 3.22 & -4.13 to 10.58 & 0.389 \\
\hline \multicolumn{4}{|l|}{ Mental component summarył } \\
\hline Intercept & 54.95 & 52.30 to 57.59 & $<0.001$ \\
\hline Month since initial injury & -0.26 & -0.36 to -0.17 & $<0.001$ \\
\hline Regional anesthesia & 0.73 & -1.75 to 3.21 & 0.564 \\
\hline \multicolumn{4}{|l|}{ Physical component summarył } \\
\hline Intercept & 38.36 & 35.78 to 40.94 & $<0.001$ \\
\hline Month since initial injury & 0.52 & 0.43 to 0.61 & $<0.001$ \\
\hline Regional anesthesia & -0.07 & -2.51 to 2.36 & 0.954 \\
\hline \multicolumn{4}{|c|}{ Patient Health Questionnaire 9-Item§ } \\
\hline Intercept & 4.32 & 3.40 to 5.25 & $<0.001$ \\
\hline Month since initial injury & 0.00 & -0.03 to 0.04 & 0.997 \\
\hline Regional anesthesia & 0.40 & -0.47 to 1.26 & 0.364 \\
\hline
\end{tabular}

Table 3 Continued

\begin{tabular}{lrlr}
\hline & $\boldsymbol{\beta}$ & \multicolumn{1}{l}{$95 \% \mathrm{Cl}$} & P value \\
\hline PTSD Check List (continuous) & & & \\
\hline Intercept & 28.39 & 25.71 to 31.07 & $<0.001$ \\
Month since initial injury & 0.07 & -0.02 to 0.16 & 0.126 \\
Regional anesthesia & 0.35 & -2.19 to 2.89 & 0.788 \\
\hline
\end{tabular}

All models included a covariate for ISS and length of hospitalization. See online supplementary table for more detail.

*Neuropathic Pain Scale outcomes measure sensations of neuropathic pain from 0 , no pain, to 10 , the wrost pain imaginable.

†Treatment Outcomes of Pain Survey outcomes fear avoidance, objective family social disability, pain symptom, and solicitous response are measured from 100, the greatest possible amount of that concept (worst score), to 0 , none of that concept (best score). For outcomes of patient satisfaction with care, patient satisfaction with outcomes, and life control, a score of 100 indicates the best health or greatest satisfaction (best score) and 0 indicates worst health or worst satisfaction (worst score).

¥Embedded in the Treatment Outcomes of Pain Survey for this study, the Short Form Health Survey 36-Item component summary scores are aggregates of individual domains measured from 1 , poor health, to 5 , very good health that have been transformed to weighted z-scores, multiplied by 10 and added to 50 to linearly transform the summary scores on the T-score metric, which has a mean of 50 and a SD of 10 for the US general population. Higher T-scores indicate a positive improvement in a domain. §Patient Health Questionnaire scores are a sum of the nine depressionspecific questions scores from 0 , no depressive symptoms at all, to 3 , with depressive symptoms experienced nearly every day, allowing for scores to range from 0 to 27 .

IPTSD Check List measures the frequency of 17 symptoms of PTSD in the past month on a scale of 1, not at all, to 5, extremely, for a summary score ranging from 17 to 85 . Previously, a score of 30 has been suggested as a cut-point for estimating PTSD in active duty military personnel serving in OEF/OIF (https://www.ptsd.va.gov/professional/assessment/documents/ PCL_handoutDSM4.pdf).

${ }^{* *}$ Non-linear mixed effects model fit.

$95 \% \mathrm{Cl}, 95 \% \mathrm{Cl}$ of fixed effect beta coefficient; ISS, Injury Severity Scores; OEF, Operation Enduring Freedom; OIF, Operation Iraqi Freedom; PTSD, posttraumatic stress disorder.

and postcombat situation, significant differences in average pain were observed between RA groups in the first 6 months after injury and remained up to 24 months. Although not statistically significant, similar decreases in worst pain and neuropathic pain intensity were observed in the early RA group. Overall, patientreported pain outcomes generally improved for all participants despite the severity of their injuries.

Our findings expand on the utility of RA for acute pain management. For context, meta-analyses of surgical populations have shown that CPNBs provide superior analgesia postoperatively compared with general opioid-based analgesia. ${ }^{1{ }^{23}}$ Despite CPNBs being recommended for postoperative pain management by multidisciplinary experts, there are few studies examining RA use during trauma care. ${ }^{24}$ An earlier retrospective study of 126 combat-injured military personnel found that receiving RA was associated with a 1.5-point decrease in pain intensity over 7 days postoperatively. ${ }^{25}$ Our longitudinal study, with a defined control group, builds on previous cross-sectional and shorter duration observational studies, which identified RA to be associated with improvements in pain intensity and relief throughout evacuation to acute care following combat injury. ${ }^{825}$ Despite the combatrelated mechanisms of injury experienced by our participants, average pain scores at 24 months were similar to those reported in samples of civilians with moderate and severe injuries. ${ }^{26}$ This underscores the therapeutic benefits participants received from early pain management after injury. The difference in pain 
scores between groups over time poses a potentially meaningful improvement. The observational nature of this investigation, the length of follow-up, and the unique patient population studied do not conform to the meaningful difference standards commonly used in clinical trials of much shorter duration evaluating chronic pain intensity with civilian populations. ${ }^{27}$ Future work will need to evaluate the role of secondary outcomes on pain in combat-injured populations after receiving RA.

This research extends the current understanding of the longitudinal presentations of patient-reported outcomes following combat-related extremity injuries. Few studies have routinely captured health outcomes or examined the diverse nature of pain experiences in the 24 months following combat-related injury. ${ }^{28}$ Uniquely, this study measured a range of pain-related symptoms from the time of initial injury through recovery. While not statistically significant, individuals receiving early RA reported lower mean neuropathic pain quality and intensity scores as well as higher mean TOPS domain score, such as greater satisfaction with outcomes, compared with those who did not receive early RA. The improvements in secondary outcomes highlight the progress made by resilient service members throughout recovery and rehabilitation, as well as the limitations of detecting associations between RA treatment applied in the combat theater to managing complex pain years later. Commensurate with civilian literature, we found that changes in HRQOL measures were not significantly associated with receiving CPNB. ${ }^{23}$ PHQ-9 and PCL scores were below commonly used depression and PTSD screening thresholds and remained stable. However, over a third of study participants' PCL scores met PTSD criteria, a rate considerably higher than the general population.

These findings have implications for future military and civilian trauma care research. These results suggest that effective, agile pain interventions initiated close to the time of injury can play an important role in reducing future pain. Any national agenda committed to achieving zero preventable deaths after injury and curtailing trauma-related disability requires a well-trained workforce of providers capable of addressing the complex pain of injured survivors. ${ }^{29}$ There is a continued need to adequately disseminate decades of war-time generated knowledge into both domestic military and civilian trauma care settings. The injuries seen in civilian trauma centers after mass casualty events can be akin to the combat injuries sustained by the participants in this study. Future studies investigating the timely delivery of RA for optimal pain management in civilian trauma settings are needed. Studies conducted in more controlled environments, relative to the combat theater,may be able to identify trauma populations that derive greater benefits from RA and elucidate subsequent long-term outcomes.

In addition to challenges with data collection, the other limitations of this study are typical for prospective observational studies. The lack of significant differences observed in other pain outcomes may reflect the inherent variability in collecting pain measurements over time without the context of any activity participants undertook immediately prior to assessment. ${ }^{30}$ Follow-up was complicated by the dispersion of subjects across the country following discharge from service. Thus, outcome data were not available from all participants at all time points. Concerns for unmeasured confounders in observational research remain, despite our efforts to control for them in multivariable modeling. For example, discharge from military service and care facilities, as described previously, made it much harder to collect all planned outcomes from all participants at each time point. There were inherent difficulties obtaining health records from an active war zone, including the specific analgesic used in CPNBs and block duration. It is important to note that utilization of RA by military providers was undergoing rapid evolution, in terms of technology and capability, during the execution of this study. ${ }^{12}$ Throughout the study time period, there was a substantial shift in anesthesiology resident training with a greater emphasis placed on achieving competencies in a diversity of RA techniques to address the needs of patients in pain. ${ }^{31}$ No provider-level data were collected for this study to know the training backgrounds of providers who were placing CPNB in the combat theater across time or to identify provider clustering. However, the non-significant year by RA receipt interaction term indicates CPNB were being placed over time consistently in this sample as military anesthesia providers deployed or returned home. Due to advancements in pain management and military anesthesia training occurring during this study time period, Joint Trauma System Clinical Practice Guidelines currently used in the combat theater call for the use of RA to provide pain management in casualty care whenever possible. ${ }^{32}$

This observational study could not control for the multitude of variables that can influence pain outcomes across the clinical milieu combat-injured service members transition through over 2 years. Rather, this investigation was about evaluating early care interventions, specifically CPNB, being provided to combatinjured service members after integrating RA providers into health systems within an active combat zone. Obtaining information on the care provided, particularly in the combat theater, proved extremely difficult. For example, while other investigations of trauma patients receiving CPNB in civilian tertiary care settings have reported mean catheter infusions of 9 days, our observational study was unable to accurately capture the average length of placement due to limited documentation of day of initial administration of CPNB prior to arriving at definitive care. $^{2533}$ There is evidence supporting the use of RA to prevent persistent postsurgical pain, yet rarely is the duration of CPNBs reported in studies conducted in definitive care settings. ${ }^{34}$ These limitations, and the complex biopsychosocial presentation of pain, make it difficult to isolate the benefits of any one therapeutic intervention for chronic pain intensity regardless of the number of extraneous variables and possible confounders not collected.

Patient-reported pain outcomes following combat-related extremity injuries improve significantly in the first 6 months after injury and remain stable up to 24 months. These findings support our hypothesis that following combat-related extremity injuries, early blockade of peripheral pain stimuli with CPNB was associated with a larger reduction in average pain intensity 6 months postinjury and sustained up to 24 months. While seemingly marginal, modest reductions in pain intensity realized in the first few months after injury can amount to important lifetime benefits for our injured veterans. Results indicate a need to further evaluate the utility of RA for pain management in severely injured military and civilian populations. When integrated into combat casualty care, early use of RA is associated with sustained pain benefits throughout rehabilitation and recovery.

\footnotetext{
Author affiliations

Center for Health Equity Research and Promotion, Corporal Michael J. Crescenz Veterans Affairs Medical Center, Philadelphia, Pennsylvania, USA

${ }^{2}$ Biobehavioral Health Sciences, University of Pennsylvania School of Nursing, Philadelphia, Pennsylvania, USA

${ }^{3}$ Department of Anesthesiology and Critical Care, University of Pennsylvania Perelman School of Medicine, Philadelphia, Pennsylvania, United States

${ }^{4}$ Department of Military and Emergency Medicine, Uniformed Services University, Rockville, Maryland, USA
} 
${ }^{5}$ Defense and Veterans Center for Integrative Pain Management, Henry M. Jackson Foundation for the Advancement of Military Medicine, Rockville, Maryland, USA ${ }^{6}$ Center for Clinical Epidemiology and Biostatistics, University of Pennsylvania Perelman School of Medicine, Philadelphia, Pennsylvania, USA

${ }^{7}$ Department of Psychiatry, University of Pennsylvania Perelman School of Medicine, Philadelphia, Pennsylvania, USA

${ }^{8}$ Behavioral Health Department, Corporal Michael J. Crescenz VA Medical Center, Philadelphia, Pennsylvania, United States

${ }^{9}$ Department of Rehabilitation Medicine, United States Army Brooke Army Medical Center, Fort Sam Houston, Texas, USA

\section{Twitter Nicholas A Giordano @nagiordano}

Acknowledgements We thank our participants for their service and for being part of this study; thank you to our research team members, including Megan Vaughn, Mary McDuffie, Yolanda Williams, and Tiffany Huseman for their support on this project.

Contributors RMG, CCB, and RP conceived the original idea of this trial, wrote the protocol, and supervised the project. Planning, execution, and data collection of the experiment were carried out by CCB, DO, BJG, RMG, and RP. NG, LT, JTF, and WG performed the statistical analyses, interpretation, visualization, and data management. All the authors equally provided critical feedback and helped to shape the research, analysis, and writing of the manuscript.

Funding This work was supported by the US Department of Veterans Affairs (VA RRD D45064-1).

Disclaimer The views expressed in this manuscript are those of the authors and do not reflect the official policy of the Department of Veterans Affairs, the Uniformed Services University, the Department of the Army/Navy/Air Force, the Department of Defense, the United States Government, or the Henry M. Jackson Foundation for the Advancement of Military Medicine (HJF).

Competing interests None declared.

Patient consent for publication Not required.

Ethics approval Walter Reed National Military Medical Center and San Antonio Military Medical Center institutional review boards approved this study.

Provenance and peer review Not commissioned; externally peer reviewed.

Data availability statement Data are available on reasonable request.

Open access This is an open access article distributed in accordance with the Creative Commons Attribution Non Commercial (CC BY-NC 4.0) license, which permits others to distribute, remix, adapt, build upon this work non-commercially, and license their derivative works on different terms, provided the original work is properly cited, an indication of whether changes were made, and the use is noncommercial. See: http://creativecommons.org/licenses/by-nc/4.0/.

\section{ORCID iD}

Nicholas A Giordano http://orcid.org/0000-0003-0112-6214

\section{REFERENCES}

1 Institute of Medicine (US) Committee on Advancing Pain Research, Care, and Education. Relieving pain in America: A blueprint for transforming prevention, care, education, and research. Washington (DC): National Academies Press (US), 2011.

2 Mokdad AH, Ballestros K, Echko M, et al. The state of US health, 1990-2016: burden of diseases, injuries, and risk factors among US states. JAMA 2018;319:1444-72.

3 Eastridge BJ, Hardin M, Cantrell J, et al. Died of wounds on the battlefield: causation and implications for improving combat casualty care. J Trauma 2011;71(1 Suppl):S4-S8

4 Lew HL, Guillory SB, Cifu DX. Program development and defining characteristics of returning military in a Va polytrauma network site. J of Rehab Res Dev 2007;44.

5 Castillo RC, Wegener ST, Heins SE, et al. Longitudinal relationships between anxiety, depression, and pain: results from a two-year cohort study of lower extremity trauma patients. Pain 2013;154:2860-6.

6 Hoge CW, Terhakopian A, Castro CA, et al. Association of posttraumatic stress disorder with somatic symptoms, health care visits, and absenteeism among Iraq war veterans. Am J Psychiatry 2007;164:150-3.

7 Bowman WJ, Nesbitt ME, Therien SP. The effects of standardized trauma training on prehospital pain control: have pain medication administration rates increased on the battlefield? J Trauma Acute Care Surg 2012;73.
8 Buckenmaier CC, Rupprecht C, McKnight G, et al. Pain following battlefield injury and evacuation: a survey of 110 casualties from the wars in Iraq and Afghanistan. Pain Med 2009;10:1487-96

9 Holbrook TL, Galarneau MR, Dye JL, et al. Morphine use after combat injury in Iraq and post-traumatic stress disorder. N Engl J Med 2010;362:110-7.

10 Pozek J-PJ, Beausang D, Baratta JL, et al. The acute to chronic pain transition: can chronic pain be prevented? Med Clin North Am 2016;100:17-30.

11 Andreae $\mathrm{MH}$, Andreae DA. Regional anaesthesia to prevent chronic pain after surgery: a Cochrane systematic review and meta-analysis. Br J Anaesth 2013;111:711-20.

12 Harris KC, Rathmell JP. Forward-deployed anesthesiologists and pain treatment in combat support hospitals: making decisions about deployment of anesthesiologists in support of the global war on terrorism. Anesthesiology 2007;107:872-4.

13 Gerhardt RT, Reeves PT, Kotwal RS, et al. Analysis of prehospital documentation of injury-related pain assessment and analgesic administration on the contemporary battlefield. Prehosp Emerg Care 2016:20:37-44.

14 Dougherty AL, Mohrle CR, Galarneau MR, et al. Battlefield extremity injuries in operation Iraqi freedom. Injury 2009:40:772-7.

15 Baker SP, O'Neill B, Haddon Jr W, et al. The injury severity score: a method for describing patients with multiple injuries and evaluating emergency care. J Trauma Acute Care Surg 1974;14:187-96.

16 Cleeland CS, Ryan KM. Pain assessment: global use of the brief pain inventory. Singapore: Annals Acad Med, 1994.

17 Galer BS, Jensen MP. Development and preliminary validation of a pain measure specific to neuropathic pain: the neuropathic pain scale. Neurology 1997:48:332-8

18 Ho M, Lafleur J. The treatment outcomes of pain survey (tops) a clinical monitoring and outcomes instrument for chronic pain practice and research. J Pain Pal Care Pharma 2004;18:49-59.

19 Hays RD, Sherbourne CD, Mazel RM. The Rand 36-Item health survey 1.0. Health Econ 1993:2:217-27.

20 Kroenke K, Spitzer RL, Williams JB. The PHQ-9: validity of a brief depression severity measure. J Gen Int Med 2001;16:606-13.

21 Blanchard EB, Jones-Alexander J, Buckley TC, et al. Psychometric properties of the PTSD checklist (PCL). Behav Res Ther 1996:34:669-73.

22 Smith TC, Zamorski M, Smith B, et al. The physical and mental health of a large military cohort: baseline functional health status of the millennium cohort. BMC Public Health 2007;7:340

23 Ilfeld BM. Continuous peripheral nerve blocks: a review of the published evidence Anesth Analg 2011;113:904-25.

24 Chou R, Gordon DB, de Leon-Casasola OA, et al. Management of postoperative pain: a clinical practice guideline from the American pain Society, the American Society of regional anesthesia and pain medicine, and the American Society of anesthesiologists Committee on regional anesthesia, executive Committee, and administrative Council. $J$ Pain 2016;17:131-57.

25 Stojadinovic A, Auton A, Peoples GE, et al. Responding to challenges in modern combat casualty care: innovative use of advanced regional anesthesia. Pain Med 2006;7:330-8

26 Holmes A, Williamson 0, Hogg M, et al. Determinants of chronic pain 3 years afte moderate or serious injury. Pain Med 2013:14:336-44.

27 Dworkin RH, Turk DC, McDermott MP, et al. Interpreting the clinical importance of group differences in chronic pain clinical trials: IMMPACT recommendations. Pain 2009;146:238-44.

28 Melcer T, Walker J, Sechriest F V, et al. A retrospective comparison of five year health outcomes following upper limb amputation and serious upper limb injury in the Iraq and Afghanistan conflicts. PM\&R 2019;11:577-89

29 Berwick DM, Downey AS, Cornett EA. A national trauma care system to achieve zero preventable deaths after injury: recommendations from a national academies of sciences, engineering, and medicine report. JAMA 2016:316:927-8.

30 Farrar JT, Pritchett YL, Robinson M, et al. The clinical importance of changes in the 0 to 10 numeric rating scale for worst, least, and average pain intensity: analyses of data from clinical trials of duloxetine in pain disorders. J Pain 2010;11:109-18.

31 Sites BD, Chan VW, Neal JM, et al. The American Society of regional anesthesia and pain medicine and the European Society of regional anaesthesia and pain therapy joint Committee recommendations for education and training in ultrasound-guided regional anesthesia. Reg Anesth Pain Med 2009;34:40-6.

32 Dhanjal ST, Highland KB, Nguyen DM, et al. Regional anesthesia in the combat setting: are ACGME requirements enough? Mil Med 2019. doi:10.1093/milmed/ usz007. [Epub ahead of print: 22 Feb 2019].

33 Fleming I, Egeler C. Regional anaesthesia for trauma: an update. BJA Educ 2014; 14:136-41

34 Weinstein EJ, Levene JL, Cohen MS, et al. Local anaesthetics and regional anaesthesia versus conventional analgesia for preventing persistent postoperative pain in adults and children. Cochrane Database Syst Rev 2018;118. 